\title{
MULTIDIMENSIONAL COMPARATIVE ANALYSIS OF SOCIO-ECONOMIC DEVELOPMENT OF RURAL AREAS OF THE MASOVIAN PROVINCE IN YEARS 2004-2016
}

\author{
Mariola Chrzanowska' Dr. oec., Monika Zielinska-Sitkiewicz' Dr. oec., \\ Warsaw University of Life Sciences
}

\begin{abstract}
Mazowieckie province is a unique area of Poland. It is characterised by large interregional differences in its internal structure. This is an interesting research area that requires the analysis of socio-economic development in this region to be conducted in a multidimensional way.

The aim of this study is to analyse and evaluate the spatial differentiation of the level of socio-economic development of rural areas in Mazowieckie province. Iteartive method for linear ordering (modified taxonomic measure of development) was used to determine the level of socio-economic development. Analyses showed the growing developmental differences between the wealthy areas or the areas getting wealthier and poor areas. The best territorial units (top of the ranking) are located in the Warsaw Metropolitan Area, which is the largest pole of economic growth not only in the Masovian province, but also in the whole country. The second category of municipalities with the highest level of development are the municipalities located along the main routes to the capital. On the other hand, municipalities with the lowest level of development are mainly peripheral regions without good communication with the capital.
\end{abstract}

Key words: socio-economic development, rural areas, synthetic measure, Mazovian province.

JEL code: R11, 047, C49

\section{Introduction}

The socio-economic development plays an important role in the economics and economic policy of a given country, region or territorial unit. This is an extremely complex term. It is considered in eight mutually interpenetrating aspects: social, economic, technical, technological, spatial, natural, aesthetic and time (Bobrowska, Piasecka, 2005). The social development means a continuous growth of variables that are relevant to a given community. Economic development, on the other hand, concerns the increase in production, employment, investment and other values that characterize the economy quantitatively. The technical aspect includes the development of technology. This term is understood as the use of pioneer, improved machines, devices and tools in the production process. Technology development is related to this area, which is associated with the implementation of new production methods. On the other hand, spatial development is responsible for well-thought-out and diversified land development. The development of nature involves the identification of facilities and areas in need of protection. In terms of aesthetics, the idea is that the development of a given area would not only be nice, but also acceptable for everyone. Time is important in socio-economic development - long-term development is desirable, not just temporary growth. As a consequence, the study of socio-economic development is a subject to a number of studies and analyses (Wojewodzka-Wiewiorska, Dudek 2016; Drejerska, Braja 2014).

The processes of socio-economic development do not occur evenly and can only be observed in a strictly defined space. Contemporary determinants of regional development are characterized by clear differences in the level of socio-economic development in individual units (Pylak, WojnickaSycz 2016). In this context, it is worth mentioning one of the basic theories of regional development - core-periphery theory. The concept proposed in 1967 by J. Friedmann (A general theory of polarized development) helps recognize the correctness of the functioning of growth areas and economic strategy. It is based on the concepts of the core and periphery and the relations between these areas. The core is the area in which the production and service activities of 
the most competitive enterprises are located. These are mostly the central areas that dominate the surroundings. Therefore, the development of peripheries takes place as a result of the impact of the cores. This process is subordinate and consequently strengthens the domination of the fundamental centre. Core areas have great development potential and high ability to generate innovations. Their development is based on diversified effects:

- domination - taking development factors from peripheries to the core,

- information - concentration of high quality human capital and a society conducive to innovation in the core,

- feedback - some innovations evoke another,

- monopoly - a privileged position on the market and an increase in revenues thanks to the use of productive innovations (Churski 2011).

The peripheries are determined based on their connections to the core. These are areas of recession or slow development, showing significant dependence on the area of growth. However, the core-periphery division is not enough, which is why four classes of areas are distinguished:

- metropolitan areas - cores,

- development axes - band zones formed along main communication lines connecting cores,

- borderland regions - areas with diverse socio-economic situation, showing development capabilities,

- dilapidated regions - peripheries characterized by recession and population decline.

The first two of the four groups can be included in the areas of economic development. Borderland regions are areas of stagnation that have a chance to grow and in the future to join growth areas, they are called ascending peripheries. Dilapidated regions are areas of economic stagnation, subordinate in terms of development and exploited by areas of growth. They can be called descending peripheries. The areas of growth affect areas of economic stagnation through:

- the creation of market, administrative and economic dependency,

- modelling of ranking relationships, of a horizontal and vertical nature, affecting the hierarchy of the entire settlement system,

- formation of innovative impulses, which degree of reception through areas of economic stagnation depends on their innovation rate,

- strengthening the independence of areas of economic stagnation, which may lead to conflicts in relations with the area of growth,

- shaping the exchange of persons, goods and information that may lead to expansion of areas of growth and inclusion of areas of economic stagnation in their range.

The market mechanism should strive to strengthen areas of growth. At the same time, it must also affect the areas of economic stagnation, so as to increase the share of peripheries ascending in their internal structure, and to limit the contribution of the descending peripheries. The concept of cores and peripheries is distinguished by the strengthening of growth areas of various hierarchical levels in the economic area and the creation of functional relations between these areas, and the areas of economic stagnation. It is necessary for creating conditions for the spread of experience and capital from the areas of growth to areas of economic stagnation.

The Masovian province represents an area very well illustrating the core-periphery theory. There is a large economic diversification. Agriculture dominates mainly outside the Warsaw Metropolitan Area: vegetable and fruit growing, poultry and cattle breeding. There are also specialized areas of agricultural and food production, e.g. the pepper plantations are mainly in municipalities: Potworow 
and Przytyk. According to the Development Strategy of the Masovian province (2013) - the largest number of entities in the Masovian province in 2011 was engaged in trade and transport 229 thousand. Other industries in which there are numerous representatives include construction, finance, technical and culture-related services. There is also a representative of the petrochemical industry - PKN Orlen based in Plock. Masovia is also dominant in research and development, e.g. in 2011, there were 41 entities in the field of biotechnology ( $25.6 \%$ of the total number of such units in Poland) (Development Strategy..., 2013).

The Masovian province is a region that is very well developed economically and socially. However, it is struggling with large interregional differences in the internal structure. The concentration of enterprises in Warsaw or its vicinity affects the worse development of regions located away from the Warsaw agglomeration. Problems with health care and environmental protection adversely affect the residents' living conditions. In turn, extensive cultural facilities fill the demand of residents for recreation. Thus, Masovia is an interesting research area that requires that the analysis of development in this region be carried out in a multidimensional manner.

The aim of the paper is to determine the level of rural areas development in the Masovian voivodeship in 2004 and 2016 using the methods of multidimensional comparative analysis (modified version of the synthetic Hellwig TMD development measure).

The following research questions were formulated in the paper:

- in which socio-economic condition are rural areas in Masovian voivodeship?

- what kind of objects represent rural areas in Mazowieckie province according to the core periphery theory?

- what affects the high or low level of socio-economic development?

The presented results have a cognitive value, but they can also be an inspiration for regional and local authorities to use multidimensional methods, e.g. in the socio-economic diagnosis of a given territory or to assess the effects of the development policy. The most significant limitation of the study that can be identified results from a fact that the research outputs cannot be directly compared with other studies as an expert own criteria of selection of variables were applied. These selection criteria are consistent with the theoretical background so general trends and conclusions of this study can be compared with other research but not a place of a single municipality in a ranking when other rankings can use different criteria. Also a lack of relevant data on the local level is a significant limitation of such kind of analysis.

\section{Description of methods}

Linear ordering is one of methods that involves ranking objects according to one feature. In other words, the method allows to number objects from 1 to $\mathrm{n}$. The objects are ranked according to a certain criterion - usually from "the best (1) to the worst ( $n)^{\prime \prime}$. Taxonomic measures of development are applied in benchmarking and linear ordering of socio-economic objects. The research of taxonomic methods in Poland was initiated by Z. Hellwig, who in 1968 used the taxonomic measure for benchmarking the development of selected countries (Helliwg 1968). The construction of Taxonomic Measure of Development (TMD) is general, so there are no contraindications against using it in comparative analysis and linear ordering of various social (or socio-economic) phenomena. The basis of this method is to build a theoretical model of development.

The classical $T M D$ algorithm is as follows: 
- standardizing the character of variables. by transforming all of them into stimulants) ${ }^{1}$;

- normalization of diagnostic variables using formula (1)

$$
z_{i j}=\frac{x_{i j}-\bar{x}_{j}}{s_{j}}
$$

where $\bar{x}_{j}$ the arithmetic mean of variable $X{ }_{j},{ }_{j}$ the standard deviation of variable $X_{j}$

- pattern construction - an object that has the best (highest) values of diagnostic variables (see formula (2)

$$
z_{0 j}=\max _{i}\left\{z_{i j}\right\}
$$

where $z_{i j}$-normalized values observed in the whole set of data;

- determining the distance $\left(d_{i}\right)$ of each object from the pattern.

$$
d_{i}=\sqrt{\frac{1}{m} \sum_{j=1}^{m}\left(z_{i j}-z_{0 j}\right)^{2}}
$$

- Normalization of the measure is carried out using the following formula:

$$
T M D_{i}=1-\frac{d_{i}}{d_{0}}
$$

Where: $d_{0}=\bar{d}+s_{d}$

Higher TMD indicates a higher level of the phenomenon studied. In order to take into account different levels of impact of individual diagnostic variables on the studied phenomenon, weight is introduced in the process of constructing the synthetic measure of development.

The method proposed by Hellwig is not resistant to the occurrence of untypical observations, i.e., those which statistical sizes differ significantly from the others. That is why Markowska and Sokolowski (Sokolowski, Markowska 2017) proposed a modification of this method. To avoid the influence of the outlying observation on the order of other objects, $n-1$ rankings are built. After building the first one, the best element is removed from the analysed set, and the remaining ones are used to build another ranking. The procedure is repeated $n-1$ times. The resulting ranking is stable and immune to outliers.

The study presented in the paper was divided into two parts. In the first part of the analysis, the ranking of municipalities in 2004 and 2016 was created using the modified TMR measure. In the second stage, basis on first iteration three groups of municipalities were identified:

- group 3. with the lowest degree of development

$$
m_{i}<\bar{m}-s_{M}
$$

- group 2. with the medium degree of development

$$
\bar{m}-s_{M} \leq m_{i} \leq \bar{m}+s_{M}
$$

- group 1. with the highest degree of development

$$
m_{i}>\bar{m}-s_{M}
$$

${ }^{1}$ Stimulants $(S)$ : an increase in their value causes an increase in the level of the phenomenon; destimulants $(D)$ : an increase in their value causes a decrease in the level of the phenomenon; nominants: a specific value $(N)$ indicates the highest level of the phenomenon; 
It is impossible to divide final ranking in proposed way. Due to different pattern for each iteration TMR values are incomparable.

\section{Research results and discussion}

The paper presents the proposal to apply the selected method of linear ordering for analysing the development level of rural areas of the Masovian province. Information about municipalities was obtained from the Local Data Bank of the Central Statistical Office of Poland. The selection of variables was carried out in terms of their relevance to social infrastructure, selected aspects of the economic situation, demographic research, and technical infrastructure. It was also largely determined by the availability of data at the municipal level in the selected years. The study was conducted for data obtained from the Local Data Bank for 2004 and 2016.

As a result, the following information was used for the analysis:

- expenditure per capita in Section 801 - Education and upbringing,

- expenditure per capita in Section 93 Culture and protection of the national heritage,

- demographic load (people of the post-working age per 100 people at the working age),

- percentage of children aged 3-5 covered by the pre-school education,

- share of the registered unemployed in the working-age population,

- number of natural persons conducting a business activity per 1000 inhabitants (private sector),

- number of commercial companies per 1000 inhabitants (private sector),

- number of foundations, associations and social organizations per 10000 inhabitants,

- number of flats completed for use per 10000 inhabitants,

- using the installation in \% of the total population - water supply,

- using the installation in \% of the total population - sewerage.

Table 1 presents the ranking of top 10 municipalities of the Masovian province in 2004 and 2016. In 2004, Lesznowola was the leader of the ranking, and Nadarzyn in 2016. The next places in the ranking are occupied, respectively, by Michalowice and Bialobrzegi (in 2004) and by Michalowice and Izabelin (in 2016).

\section{Ranking of the best municipalities separated by means of a modified $T M D$ measure in 2004 and 2016}

Table 1

\begin{tabular}{|c|c|c|c|l|}
\hline \multicolumn{2}{|c|}{$\mathbf{2 0 0 4}$} & \multicolumn{2}{c|}{$\mathbf{2 0 1 6}$} \\
\cline { 2 - 6 } & position & \multicolumn{1}{|c|}{ commune } & position & commune \\
\hline $\mathbf{1}$ & Lesznowola & 1 & Nadarzyn \\
\hline $\mathbf{2}$ & Michalowice & 2 & Izabelin \\
\hline $\mathbf{3}$ & Bialobrzegi & 3 & Michalowice \\
\hline $\mathbf{4}$ & Raszyn & 4 & Lesznowola \\
\hline $\mathbf{5}$ & Rozan & 5 & Zelechow \\
\hline $\mathbf{6}$ & Grodzisk Mazowiecki & 6 & Blonie \\
\hline $\mathbf{7}$ & Nadarzyn & 7 & Ozarow Mazowiecki \\
\hline $\mathbf{8}$ & Grojec & 8 & Raszyn \\
\hline $\mathbf{9}$ & Mszczonow & 9 & Slupno \\
\hline & Source: author's calculation & Konstancin-Jeziorna & 10 & Konstancin-Jeziorna \\
\hline
\end{tabular}

Table 2 lists the municipalities, which in the analysed years obtained the worst rating. In both analysed periods, the only peripheral municipalities can be observed. Only the municipality of 
Strachowka is located close to Warsaw. All of the worst objects are characterised by lack of sewerage and water supply installation and lowest value of rest of characteristics.

\section{Ranking of the worst municipalities separated by means of a modified TMD} measure in 2004 and 2016

\section{Source: author's calculation}

\begin{tabular}{|c|l|c|l|}
\hline \multicolumn{2}{|c|}{2004} & \multicolumn{2}{c|}{$\mathbf{2 0 1 6}$} \\
\hline position & commune & position & \multicolumn{1}{c|}{ commune } \\
\hline $\mathbf{1}$ & Wolanow & 1 & Solec nad Wisla \\
\hline $\mathbf{2}$ & Chotcza & 2 & Chotcza \\
\hline $\mathbf{3}$ & Rosciszewo & 3 & Czerwonka \\
\hline $\mathbf{4}$ & Czarnia & 4 & Sierpc \\
\hline $\mathbf{5}$ & Nur & 5 & Dzierzgowo \\
\hline $\mathbf{6}$ & Strachowka & 6 & Ceranow \\
\hline $\mathbf{7}$ & Stoczek & 7 & Korczew \\
\hline $\mathbf{8}$ & Przylek & 8 & Raciaz \\
\hline $\mathbf{9}$ & Trojanow & 9 & Radzanow \\
\hline $\mathbf{1 0}$ & Jednorozec & 10 & Przylek \\
\hline
\end{tabular}

The spatial distribution of municipalities with low, medium and high levels of development is shown in Figure 1. One can note a clear influence of Warsaw on the dynamic development of neighbouring municipalities. In addition, it is worth noting that the Warsaw Metropolitan Area is indicated as the largest pole of economic growth not only in the Masovian voivodeship, but also in the whole country (Dziemianowicz et al., 2014). Role of Warsaw Metropolitan Area was analysed and underlined by other Authors (Pomianek 2017; Stanny 2012; Chrzanowska M. Zielińska-Sitkiewicz M., 2017). Municipalities with the lowest level of development are mainly peripheral ones without good communication and with the capital. These problems can be observed in whole Poland and also underlined by other Authors (Rosner 2010; Bański, Czapiewski 2008).
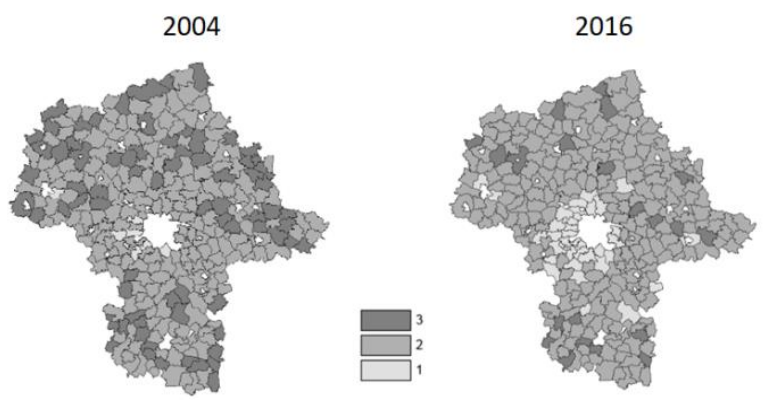

Fig. 1. Division of municipalities created using classical TMD measure in 2004 and 2016

\section{Conclusions}

The last several years are characterized by dynamic social and economic development of the country. However, it is accompanied by the processes of spatial polarization.

The following answers for research questions can be formulated.

- Spatial polarization of development process across investigated municipalities can be observed in the analysed period. It means that we can find both wealthy areas developing due to utilization of their potential and good market condition as well as less developed areas (problem areas) which for various reasons remain economically stagnant.

- Spatial diversification of rural development in Mazovian province explains the order of centreperiphery axis. Areas with a higher level of socio-economic development (municipalities with the 
highest values of the presented measures of linear ordering) are a part of the Warsaw Metropolitan Area (WMA). The second category of municipalities with the highest level of development are the municipalities located along the main routes to the capital. They are the development axes and their high level of development is a consequence of their excellent location.

- According to core periphery theory, one can classify second group of rural areas as borderland regions. There are areas with diverse socio-economic situation and we cannot determine their coherent conditions and descriptions. The municipalities belonging to the third group, are typical dilapidated regions characterized by the lowest socio and economic indicators.

- Looking deeper into causes of such grouping, one can notice that rural areas which belong to third group are characterised by a lack of water supply and sewerage systems, although it can be understandable in a situation of a low population density, a low number of number of commercial companies and number of commercial companies. On the other hand, the best rural areas are characterised by high level of all stimulants.

\section{Bibliography}

1. Banski, J., Czapiewski, K.L. (2008), Ekspertyza. Identyfikacja i ocena czynnikow sukcesu spolecznogospodarczego na obszarach wiejskich. (Expertise. Identification and Evaluation of Socioeconomic Success Factors in Rural Areas), Instytut Geografii i Przestrzennego Zagospodarowania, Warsaw.

2. Bobrowska A., Piasecka A. (2005), The Socio-economic Situation of the Region and Unemployment on the Example of the Province Opole. In "Competitiveness of the labour market and its entities", ed. D. Kopycinska, Szczecin.

3. Chrzanowska, M., Zielińska-Sitkiewicz, M. (2017) Evaluation of Spatial Differentiation of Socio-Economic Development of Rural Mazowieckie province in years 2004-2016, Proceedings of RURAL DEVELOPMENT 2017: Bioeconomy Challenges pp. 944-948.

4. Churski P. , (2011) Obszary wzrostu i obszary stagnacji gospodarczej w Polsce - kontekst teoretyczny (Areas of Growth and Areas of Economic Stagnation in Poland - Theoretical Context). In "Zroznicowania regionalne w Polsce" Biuletyn KPZK PAN, ed. Churski, P. , Notebook 248, Warsaw 2011, pp. 9- 12.

5. Drejerska, N., Braja, M., (2014) Local Self-Governments as Actors in Local Development - a Perspective of Inhabitants of the Warsaw Suburban Area. Agrarian Perspectives XXIII.: the Community-led Rural Development. Proceedings of the 23th international scientific conference. Prague, Czech Republic, pp. 271-277.

6. Dziemianowicz, W., Mackiewicz, M., Szmigiel-Rawska, K. (2014): Diagnoza obszaru metropolitalnego Warszawy. Raport syntetyczny (Diagnosis of the Metropolitan Area of Warsaw. Synthetic report). Geoprofit, Ecorys, Warsaw.

7. Hellwig, Z. (1968) Zastosowanie metody taksonomicznej do typologicznego podzialu krajow ze względu na poziom rozwoju oraz zasoby i strukturę wykwalifikowanych kadr (Use of Taxonomic Method for the Typological Division of Countries Based on Their Level of Development and the Resources and Rtructure of Qualified Personnel). Statistical Review 15.4.

8. Pomianek, I., (2017) Socio-economic Development in Poland. Warsaw Metropolitan Area and the Rest of Mazovieckie Voivodeship. In "Rural development and entrepreneurship: bioeconomy production and co-operation in agriculture". Proceedings of the International Scientific Conference. Jelgava, pp. 153-160.

9. Pylak, K., Wojnicka-Sycz, E. (2016) Transforming Innovation Models to Change the Development Paths of Less-Developed Regions. Procedia Engineering, Volume 161 (2016), pp. 2179-2183.

10. Rosner, A. (2010) Zroznicowanie przestrzenne rozwoju spoleczno-gospodarczego polskiej wsi i tendencje jego zmian. (Spatial Dversification of the Social and Economic Development of the Polish Countryside and Tends of its Changes) Kancelaria Senatu, Biuro Analiz i Dokumentacji. Warszawa 2010.

11. Sokolowski, A., Markowska, M. (2017) Iterative method for linear ordering of multidimentional objcts. Statistical Rewiev LXIV No2 pp. 153-162.

12. Stanny, M. (2012) Poziom rozwoju spoleczno-gospodarczego obszarow wiejskich w Polsce - pomiar zjawiska zlozonego (The Level of Socio-economic Development of Rural Areas in Poland - Measurement of a Complex Phenomenon). In "Rozwoj wsi i rolnictwa w Polsce. Aspekty przestrzenne i regionalne" pp. 1-22.

13. Strategia rozwoju wojewodztwa mazowieckiego do 2030 roku. Innowacyjne Mazowsze (TheDevelopment Strategy of the Masovia Province until 2030). Innovative Mazovia, Marshal's Office of the Masovian Province, Warsaw 2013.

14. Wojewodzka-Wiewiorska, A., Dudek, H. (2016) Dynamics of Rural Areas Development in Poland; Convergence Analysis. Research for Rural Development 2016, volume 2, Proceedings of 22nd Annual International Scientific Conference, Jelgava, pp. 99-105. 